\title{
Review Article \\ Engineered Nanomaterials: Knowledge Gaps in Fate, Exposure, Toxicity, and Future Directions
}

\author{
Arun Kumar, ${ }^{1}$ Prashant Kumar, ${ }^{2,3}$ Ananthitha Anandan, ${ }^{1}$ Teresa F. Fernandes, ${ }^{4}$ \\ Godwin A. Ayoko, ${ }^{5}$ and George Biskos ${ }^{6,7}$ \\ ${ }^{1}$ Department of Civil Engineering, Indian Institute of Technology New Delhi, Hauz Khas, New Delhi 110016, India \\ ${ }^{2}$ Department of Civil and Environmental Engineering, Faculty of Engineering and Physical Sciences (FEPS), \\ University of Surrey, Guildford GU2 7XH, UK \\ ${ }^{3}$ Environmental Flow (EnFlo) Research Centre, FEPS, University of Surrey, Guildford GU2 7XH, UK \\ ${ }^{4}$ School of Life Sciences, Heriot-Watt University, Edinburgh EH14 4AS, UK \\ ${ }^{5}$ Nanotechnology and Molecular Sciences, School of Chemistry, Physics and Mechanical Engineering, \\ Queensland University of Technology, Brisbane, QLD 4001, Australia \\ ${ }^{6}$ Department of Environment, University of the Aegean, University Hill, 81100 Mytilene, Greece \\ ${ }^{7}$ Faculty of Applied Sciences, Delft University of Technology, 2628 BL Delft, The Netherlands
}

Correspondence should be addressed to Prashant Kumar; p.kumar@surrey.ac.uk

Received 22 January 2014; Revised 3 April 2014; Accepted 4 April 2014; Published 12 May 2014

Academic Editor: Marinella Striccoli

Copyright (C) 2014 Arun Kumar et al. This is an open access article distributed under the Creative Commons Attribution License, which permits unrestricted use, distribution, and reproduction in any medium, provided the original work is properly cited.

\begin{abstract}
The aim of this study is to identify current knowledge gaps in fate, exposure, and toxicity of engineered nanomaterials (ENMs), highlight research gaps, and suggest future research directions. Humans and other living organisms are exposed to ENMs during production or use of products containing them. To assess the hazards of ENMs, it is important to assess their physiochemical properties and try to relate them to any observed hazard. However, the full determination of these relationships is currently limited by the lack of empirical data. Moreover, most toxicity studies do not use realistic environmental exposure conditions for determining dose-response parameters, affecting the accurate estimation of health risks associated with the exposure to ENMs. Regulatory aspects of nanotechnology are still developing and are currently the subject of much debate. Synthesis of available studies suggests a number of open questions. These include (i) developing a combination of different analytical methods for determining ENM concentration, size, shape, surface properties, and morphology in different environmental media, (ii) conducting toxicity studies using environmentally relevant exposure conditions and obtaining data relevant to developing quantitative nanostructure-toxicity relationships (QNTR), and (iii) developing guidelines for regulating exposure of ENMs in the environment.
\end{abstract}

\section{Introduction}

Production and demand of engineered nanomaterials (ENMs) embedded in consumer products are growing significantly in the current years $[1,2]$. ENMs can be directly released into the air, water, sediment, and soil media during their manufacturing, use, and disposal [3-9]. Nanosize particles are also sometimes unintentionally formed, such as those arising from the combustion of fossil fuels in motor vehicles and industries [3, 4]. In this review, ENMs refer to particulate materials having at least one of three dimensions in the $1-100 \mathrm{~nm}$ size range (nanoscale). In contrast, nanoparticles are particulate materials with all three dimensions in the nanoscale.

ENMs are currently considered as an emerging class of environmental contaminants. Recent research advances have (i) improved analytical capabilities for detecting them in different environmental media, (ii) increased availability of related toxicity data, and (iii) increased public awareness. Nevertheless there are still many open questions that need to be answered in order to fully understand their origin, fate, and toxicity.

ENMs pose risk to human health and the environment via oral, inhalation, and dermal exposure routes [10-15]. 
Table 1 summarises the key findings of recent studies related to their exposure assessment. These studies were selected to provide information about research trends in the area of risk assessment of different ENMs by means of different exposure routes. Most of these studies have focused on the framework development for (i) estimating exposure doses and risks from oral and inhalation exposure routes, (ii) prioritising nanomaterials for monitoring and risk estimating purposes, and (iii) identifying research strategies for intelligent testing of ENMs for nanosafety. Furthermore, results of toxicity studies suggest that ENMs can cross the cell membrane and induce toxic effects on different organs [16-19]. For example, $\mathrm{TiO}_{2}$ nanoparticles have been observed to induce DNA and chromosomal damage in the liver $[13,20]$. These effect-based studies also indicate that ENMs exert different toxicities in a particular target organ depending on their properties. This highlights the need for further investigations related to the exposure of ENMs.

To estimate the environmental and human health risks associated with ENM exposure, information about their size, shape, and the dose-response relation is required [37, 44]. The methodology suggested by the standard United States National Research Council $[45,46]$ proposes four steps for performing environmental and human health risk assessment (EHHRA) of chemicals and metals: (i) hazard identification, (ii) exposure assessment, (iii) dose-response assessment, and (iv) risk characterisation. A few studies have attempted to apply some of these steps for estimating risks of exposure to ENMs (Table 1). However, very few studies have carried out exhaustive risk assessment process for ENMs, probably due to the lack of required information on their fate, exposure, and toxicity.

The aims of this article are to highlight present knowledge gaps in environmental fate, exposure, and toxicity of ENMs. The suitability of currently available toxicity data in conducting EHHRA is also analysed. Issues identified in this study can help in developing efforts for addressing current data gaps for ENMs which can aid decision makers in the policy making process.

\section{Scope}

There are two main sources of nanomaterials in the environment: natural and anthropogenic. Natural sources include but are not limited to volcanoes, viruses, ocean spray, dust storms, bacteria, and bush fires. Anthropogenic sources fall into two categories: unintentionally produced nanomaterials such as those from combustion aerosols, particularly motor vehicle exhaust emission, coal fly ash, and wielding operations and intentionally produced nanomaterials with tailored properties. These may include nanowires, nanotubes, quantum dots, and fullerenes, mostly composed of metals and metal oxides [47]. In addition, nanoparticles can be incidentally formed in both of these categories [38]. This review focuses on four important aspects of the intentionally produced group of ENMs. These include (i) characterisation and application of ENMs, (ii) assessment of exposure to ENMs, (iii) hazard assessment, and (iv) environmental regulations. A literature review of published reports and journal articles is compiled to map the existing knowledge and to identify current gaps. The reviewed studies include only key literature to highlight the covered topics and do not represent the complete list of all published studies so far due to the reasons of brevity. The concluding section presents issues on different aspects and future research needs.

\section{Characterisation and Application of Nanomaterials}

3.1. Characterisation of ENMs. ENMs can be characterised using different techniques. Microscopy, in particular, has been exceptionally useful in providing information about the size and morphology of nanomaterials [48]. Scanning and transmission electron microscopy (SEM and TEM, resp.), atomic force microscopy (AFM), scanning probe microscopy (SPM), and scanning tunnelling microscopy (STM) have all been extensively employed to observe morphological, compositional, and structural features of a wide range of nanomaterials. SEM is a versatile technique that can determine the morphology whilst TEM can be used for the observation of the finest details of the internal structure of materials [49]. High resolution images of the morphology and topography of a sample can be obtained and compositional analysis of a material can also be carried out by monitoring secondary X-rays produced by the electron-specimen interaction.

A number of other methods are also available for the characterisation of nanomaterials in air [50]. These include their characterisation in terms of particle concentration and size distribution by the condensation particle counter (CPC), differential mobility particle sizer (DMPS), differential mobility spectrometer (DMS), fast mobility particle sizer (FMPS), electrical low pressure impactor (ELPI), and scanning mobility particle sizer (SMPS) $[50,51]$, as discussed in Section 4. The Brunauer, Emmett, and Teller (BET) method is commonly used to evaluate the gas adsorption data and generate information about specific surface area and pore size of various types of nanoparticles [52]. Thermogravimetric analysis (TG) is conveniently used to determine physical changes in materials. This technique provides quantitative measurement of mass change associated with transition and thermal degradation in the materials [53]. Characteristic thermogravimetric curves are given for specific materials and chemical compounds due to unique sequence from physicochemical reactions occurring over specific temperature ranges and heating rates. Vibrational spectroscopy techniques, including the Fourier transform infrared (FTIR), the near-infrared, and the Raman spectroscopy, have also been used to characterise nanomaterials. For example, LópezLorente et al. [54] recently described the use of G-/D-band intensity ratios in the Raman spectroscopic measurements for the determination of the purity of carbon nanotube samples. In addition, X-ray diffraction is currently being used for determining crystallinity of nanomaterials [55]. This information is especially important in toxicity studies as mineralogical phase of nanomaterials can also influence toxic effects [56]. 


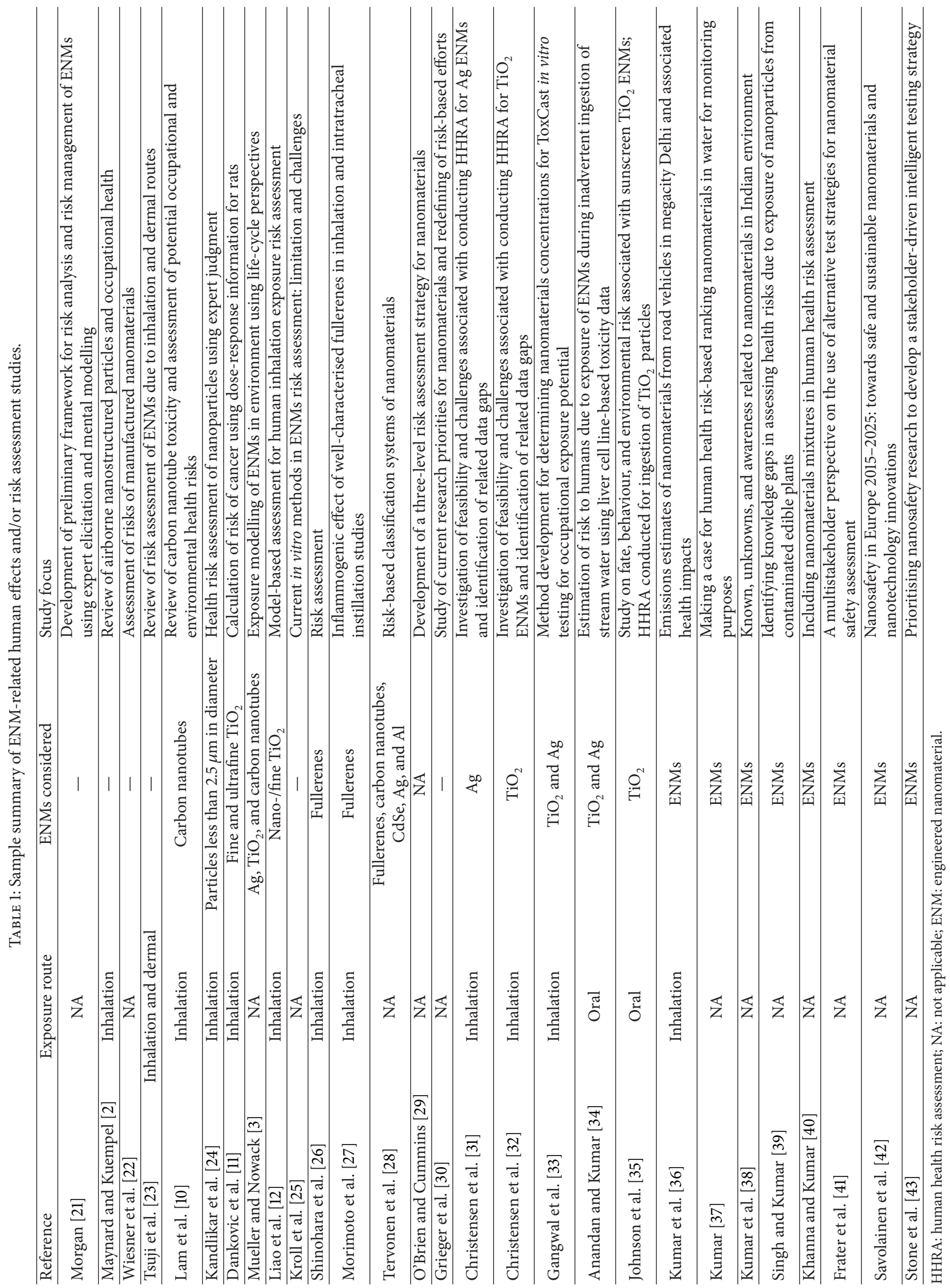


3.2. Applications of ENMs. The list of areas of human endeavour to which nanomaterials have been applied is growing rapidly. Many of these applications are a result of the special properties of nanomaterials such as their electrical, catalytic, mechanical, surface plasmon resonance and antimicrobial properties $[5,57]$. Some applications include sensors, thermoelectric materials, photocatalysts, dye-sensitised solar cells, and products such as paints, plastics, sprays, cleaning agents, coatings, sunscreens, films, packing materials, nutraceuticals, and materials for drug delivery to name a few (see, e.g., Sadik et al. [48] and Goesmann and Fledmann [58]). Exposure to nanomaterials may occur during the fabrication and various application and disposal stages of the ENMcontaining products, as discussed in Section 4.

\section{Assessment of Exposure to ENMs}

To assess human exposure to ENMs during the different stages of the life cycle of ENM-containing products, there is need to estimate their quantities when released to the environment together with toxicity-related parameters such as their size, morphology, and chemical composition. Although the field of ENM monitoring is yet not established, it draws from the existing detection and characterisation methods for monitoring particle pollution (e.g., measuring airborne nanoparticles in the air).

Inhalation of airborne ENMs is one the most important routes of entrance into the human body [59]. This is because these nanosized particles suspended in the air can spread over long distances from the point of their release, resulting in uncontrollable human exposure. ENMs can also be disposed to the environment in liquid suspensions (e.g., wastewater) and in solid media (i.e., wastewater sludge). Human exposure to ENMs from liquid and solid media is possible through swallowing or direct contact with the skin. Human exposure to the ENMs released into the terrestrial environment is less likely to occur, mainly due to their immobility.

4.1. Measuring ENMs in the Air. Nanosized particles can be released into the breathing air by both exhaust [50, 60-64] and nonexhaust sources $[60,62,65-68]$. These nanoscale particles undergo a number of physiochemical transformations $[69,70]$, resulting in both spatial and temporal variation in their concentrations in both indoor [71-74] and outdoor $[69,70,75]$ ambient environments. Nevertheless, it is still challenging to apportion the fraction of the ENMs in the total nanoscale particulate material present in the atmospheric environment [67].

The optical and electrical mobility detection techniques used to measure the natural and combustion-derived nanoparticles in ambient air are also used to measure the concentration of ENMs [50]. Optical techniques rely on the growth of nanomaterials by means of condensation and their subsequent counting by measuring the light they can scatter. The condensation particle counters (CPCs [76]) are widely used for monitoring and research purposes. Although CPCs can measure extremely low concentrations, their detection efficiency decreases markedly for materials having diameters below $\sim 3 \mathrm{~nm}[77]$.
An alternative to optical counting is to measure the current produced by particles having a known charge distribution using an aerosol electrometer (AE [78]). The number concentration of the sampled nanomaterials can be estimated using the current inducted by the collection of the charged particles on an electrometer filter, the flow rate through the $\mathrm{AE}$, and the charge distribution on the particles. The charge distribution of particles can be controlled by using an aerosol particle charger [79] operating upstream of the AE. Compared to the CPCs, the AEs can detect particles of any size. However, the threshold concentration for producing a signal above the signal-to-noise ratio is of the order of a few tens to hundreds of particles per $\mathrm{cm}^{3}$ for typical flow rates used through the AEs.

Sizing of particles in the gas phase can be achieved by a number of techniques depending on the desired range [80]. The most efficient instrument for determining the size of particles in the nanosize regime is the differential mobility analyzer (DMA [81]). DMAs classify airborne particles based on their electrical mobility, which by knowing the charge distribution and the morphology of the particles can be used to estimate their size. Although a wide range of DMA designs have been described in the literature [82], the cylindrical DMA is routinely used in combination with CPCs for measuring aerosol particle size distribution. To do so, the operating conditions (mainly the electric field strength) of the DMAs are increased in steps or continuously scanned to select particles of different sizes before being counted by the CPC. Typical scanning times of these systems take from a few seconds to a few minutes, depending on the desired resolution of the measurements [83]. Recent advances in the field have led to DMAs [84-86] and mobility spectrometers $[50,79]$ that can simultaneously classify particles in different size ranges, thereby reducing the time required to measure the entire size distribution of the particles in subsecond time fractions.

The pulmonary toxic effects induced by inhalation of ENMs are best correlated with the surface area rather than the concentration of the particles [87]. Instruments that can directly measure the surface rather than the number or the mass of the particles are already available in the market. These instruments rely on the attachment of ions or radioactive species onto the surface of particles and measuring of their current or radioactivity, respectively $[88,89]$. In accordance with recent guidelines defining benchmarks or reference threshold values, surface area monitors that rely on the attachment of ions on the particles are also used to determine the mean particle diameter and the number concentration under the assumption that those are spherical [90]. Given that many types of nanomaterials do not have a spherical shape, the estimation of the surface area by these instruments can be misleading.

One of the greatest challenges in monitoring the concentration of ENMs in the air is to distinguish them from already present background nanomaterials, which can also vary in concentration, size, morphology, and composition, depending on the nature of natural and anthropogenic sources. Online distinction between engineered and background nanomaterials can be made by probing their intrinsic 
properties such as morphology, solubility, and volatility, provided that these are detectably different among the two species. Tandem differential mobility analysis (TDMA [91]) can also be used to measure the intrinsic properties of particles such as morphology, vapour uptake, and volatility $[92,93]$. Information on the chemical composition or the structure of the airborne nanomaterials can also be obtained by offline techniques such as electron microscopy [94]. Electron microscopes can also be used for determining the elemental composition of nanoparticles, using techniques such as electron dispersive X-ray (EDX) spectrometry [95, 96]. These techniques, however, are time-consuming, expensive, of high complexity, and therefore inappropriate for systematic monitoring.

4.2. Measuring ENMs in the Aquatic Environment. Methods for characterising nanomaterials suspended in liquid media have been developed over the past decades in view of monitoring and controlling their synthesis by liquid-based techniques. Dynamic light scattering (DLS) is the most widely used technique for measuring the size and shape of nanoparticles in liquid suspensions [97]. In DLS, the solution sample is illuminated by a monochromatic light source, and the light scattered by the particles is continuously measured by a photodetector. The recorded scattering fluctuations are then processed in order to determine the translational and rotational diffusion coefficients of the particles, which in turn are used to determine their size and shape [98]. A drawback of DLS is that the larger particles in the samples can mask the signal from the nanoparticles during the measurement [99]. Another drawback is that they are not suitable for the assessment of nanofibres or nanorods.

Another way of measuring the size distribution of nanoparticles in liquid suspensions is by tracking and analysing their motion. Nanoparticle tracking analysis (NTA) measures the scattering generated from particles undergoing Brownian motion in order to estimate their diffusion coefficients [100]. Although the signal of the larger particles in NTA can also mask the signal produced by the smaller particles due to their stronger scattering, the effect is less important than in the DLS [101]. As a result NTA is preferred to DLS for measuring nanosized particles.

Another technique for measuring particles with diameters down to the nanometer size range is flow field-flow fractionation (flow FFF [102]). In Flow FFF, the particles are separated in a crossflow channel, where larger particles are immobilised in an expanding channel faster than the smaller ones due to differences in their diffusivity [103]. A variation of this method is the asymmetric flow FFF (AF4), which is capable of fractionating particles and macromolecules having diameters down to $2 \mathrm{~nm}$ [104]. AF4 can separate particles with high resolution, thereby giving unique characterisation possibilities for nanoparticles suspended in liquid media.

\section{Hazard Assessment}

5.1. Toxicity Data Availability. Many studies are currently focusing on understanding toxic effects of ENMs in in vitro and in vivo studies on different species (rats, fishes, algae, daphnids, and bacteria, amongst others). Among these studies, rats as animal models are used for obtaining reference doses. Very few toxicity studies are currently available which provide complete information on experimental conditions (i.e., nanoparticles characteristics, animal- or cell line-related information, exposure duration and frequency, and exposure medium and endpoints observed). To illustrate this aspect, summary of toxicity studies on nano- $\mathrm{TiO}_{2}$-based ENMs for oral and inhalation exposure routes is presented in Tables 2 and 3, respectively. Review of these studies indicates that different works have used varying experimental conditions and endpoints for observing effects, making it challenging to obtain data for systematic comparison and risk estimation purposes. For example, there is a lack of detailed dataset from toxicological and epidemiological studies on inhalation toxicity to humans. To circumvent this issue, animal data are used for determining toxicity parameters for human external and lung doses [44]. Although use of animal data for reference dose quantification is a standard methodology in the absence of toxicity data on humans, there is inherent uncertainty in extrapolating findings on animals to humans (i.e., interspecies uncertainty). Further, there exists a difficulty in finding out toxicity studies with detailed information on experimental descriptions for comparison purposes. For example, O'Brien and Cummins [105] screened many studies of $\mathrm{TiO}_{2}$ particles to identify toxicity works that are suitable for providing ingestion and inhalation-related animal data. After a thorough review, they were able to finally use findings from the following studies related to (i) inhalation (endpoint: lactate dehydrogenase (LDH) test [106108]) and (ii) ingestion (endpoint: liver kidney and spleen coefficient; blood biomarker assays and histopathological examination [109]). These observations clearly indicate a need for standardising toxicity conditions for observing a given endpoint and facilitating easy comparison of toxicity data [110]. During the use of animal toxicity data, there is also a need for the accounting of the effects of animal species or strain on toxic effects and subsequently on dose-response parameters. For example, Kuempel et al. [44] discussed the exposure of ultrafine and fine $\mathrm{TiO}_{2}$ particles to rat strains (Sprague-Dawley, Wistar, Fischer 344, and Long Evans). They found a difference in observed lung burden doses, indicating a need to consider the effect of rat strain type on doseresponse parameter since this can influence benchmark dose limit values that are normally calculated using dose-response data.

Furthermore, some researchers have studied ENM-based toxicity on cell lines (see Tables 2 and 3). These studies are easier to conduct than in vivo studies. However, findings of in vitro studies cannot be directly used to understand toxicity of ENMs to the target organs as toxic effects on cell lines cannot represent toxic effects on the whole target organ. These data are sometimes less useful than those obtained from animal models (e.g., rats) as findings of toxicity studies on cells cannot be easily extrapolated for determining toxicity to either human cell line or to human target organ. However, this step is not required if toxicity data is directly available for human cell line and/or human organs. There is a need for identifying mechanisms for extrapolating the findings of 
TABLE 2: Oral toxicity of $\mathrm{TiO}_{2}$ to rats and in vitro data on rat cell lines.

\begin{tabular}{lcll}
\hline Reference & Exposed animals/cell line type & Experimental design & Endpoint \\
\hline Hussain et al. [111] & BRL 3A rat liver cell line & $\begin{array}{l}\text { Exposure of } \mathrm{TiO}_{2} \text { particles for 24 hours } \\
\text { in vitro to } 40 \mathrm{~nm} \mathrm{TiO}_{2} \text { particles }\end{array}$ & Cytotoxicity; mitochondrial function \\
\hline Trouiller et al. [13] & Rats & $\begin{array}{l}\text { Exposure of } \mathrm{TiO}_{2} \text { particles (21 nm size, } \\
75 \% \text { anatase, and 25\% rutile) through } \\
\text { drinking water }\end{array}$ & $\begin{array}{l}\text { DNA single and double strand breakage; } \\
\text { chromosomal damage in vivo; DNA } \\
\text { deletions in offspring }\end{array}$ \\
\hline Kocbek et al. [112] & HEK cells & $\begin{array}{l}\text { Effect of } \mathrm{TiO}_{2} \text { and } \mathrm{ZnO} \text { particles on HEK } \\
\text { cells in vitro }\end{array}$ & Cytotoxicity \\
\hline
\end{tabular}

ENM: engineered nanomaterial; HEK cells: human embryonic kidney cells; ROS: reactive oxygen species.

TABLE 3: Inhalation toxicity of $\mathrm{TiO}_{2}$ to rats and in vitro data on rat cell lines.

\begin{tabular}{|c|c|c|c|}
\hline Reference & $\begin{array}{l}\text { Exposed animals/cell } \\
\text { line }\end{array}$ & Experimental design & Endpoint \\
\hline Henrich et al. [113] & $\begin{array}{l}\text { Wistar rats; } \\
\text { inhalation }\end{array}$ & $\begin{array}{l}\text { Chronic inhalation }(24 \text { months }) ; 10 \mathrm{mg} / \mathrm{m}^{3} \\
\mathrm{TiO}_{2} \text { particles }(15-40 \mathrm{~nm} \text { size; mass-median } \\
\text { aerodynamic diameter }=800 \mathrm{~nm})\end{array}$ & $\begin{array}{l}\text { Carcinogenicity; histology; DNA addicts; } \\
\text { alveolar lung clearance }\end{array}$ \\
\hline Bermudez et al. [106] & $\begin{array}{l}\text { Hamster and rat; } \\
\text { inhalation }\end{array}$ & $\begin{array}{l}\text { Subchronic inhalation }(3.25 \text { months); } \\
10-250 \mathrm{mg} / \mathrm{m}^{3} \text { pigmentary } \mathrm{TiO}_{2} \text { particles } \\
\text { (assumed diameter }=300 \mathrm{~nm} ; \text { mass-median } \\
\text { aerodynamic diameter }=1400 \mathrm{~nm} \text { ) }\end{array}$ & $\begin{array}{l}\text { Inflammatory response; cytotoxicity; lung } \\
\text { cell proliferation; histopathology }\end{array}$ \\
\hline Höhr et al. [108] & Rat; instillation & $\begin{array}{l}16 \mathrm{~h} \text { instillation; } 1-6 \mathrm{mg}(\text { diameter }= \\
20-30 \mathrm{~nm} \text { and } 180 \mathrm{~nm})\end{array}$ & $\begin{array}{l}\text { Acute inflammatory response; cell } \\
\text { damage }\end{array}$ \\
\hline Bermudez et al. [107] & $\begin{array}{l}\text { Hamster and rat; } \\
\text { inhalation }\end{array}$ & $\begin{array}{l}\text { Subchronic inhalation }(13 \text { weeks }) \\
0.5-10 \mathrm{mg} / \mathrm{m}^{3} ; \text { diameter }=21 \mathrm{~nm} ; \\
\text { mass-median aerodynamic } \\
\text { diameter }=1370 \mathrm{~nm})\end{array}$ & $\begin{array}{l}\text { Inflammatory response; cytotoxicity; lung } \\
\text { cell proliferation; histopathology }\end{array}$ \\
\hline Renwick et al. [114] & Rat; instillation & $\begin{array}{l}24 \mathrm{~h} \text { instillation; } 0.125-0.5 \mathrm{mg} \\
(\text { diameter }=29 \mathrm{~nm} \text { and } 250 \mathrm{~nm})\end{array}$ & $\begin{array}{l}\text { Inflammatory response; epithelial injury; } \\
\text { alveolar macrophage toxicity; lung } \\
\text { clearance }\end{array}$ \\
\hline Warheit et al. [115] & Rat; instillation & $\begin{array}{l}24 \mathrm{~h} \text {, 1-week, 1-month, and 3-month } \\
\text { instillation; } 129.4 \mathrm{~nm} ; 149.4 \mathrm{~nm} ; 136 \mathrm{~nm} \text {; } \\
382 \mathrm{~nm}\end{array}$ & $\begin{array}{l}\text { Bronchoalveolar lavage (BAL) fluid } \\
\text { inflammatory markers; cell proliferation; } \\
\text { histopathology }\end{array}$ \\
\hline Grassian et al. [116] & Rat; inhalation & $4 \mathrm{~h}$ duration and 10-day duration; $3.5 \mathrm{~nm}$ & $\begin{array}{l}\text { Total protein content; LDH activity; } \\
\text { inflammatory cytokines; histopathology }\end{array}$ \\
\hline Li et al. [117] & Rat; inhalation & Three-day inhalation; $3 \mathrm{~nm} ; 20 \mathrm{~nm}$ & $\begin{array}{l}\text { BAL fluid biochemical parameters; } \\
\text { histopathology }\end{array}$ \\
\hline Lui et al. [118] & Rat; instillation & One-week instillation; $5-50 \mathrm{~nm}$ & $\begin{array}{l}\text { Histopathology; blood biochemical } \\
\text { parameters; LDH, alkaline phosphatase, } \\
\text { and acid phosphatase activity; alveolar } \\
\text { macrophage phagocytotic ability }\end{array}$ \\
\hline Falck et al. [56] & $\begin{array}{l}\text { Bronchial cells } \\
\text { (BEAS 2B) }\end{array}$ & $\begin{array}{l}\text { Exposure to } 8 \text { doses }\left(1-100 \mu \mathrm{g} / \mathrm{cm}^{2}\right) \text { of } \mathrm{TiO}_{2} \\
\text { particles: (1) nanorutile, }(2) \text { anatase with size } \\
<25 \mathrm{~nm} \text {, and (3) fine rutile with size }<5 \mu \mathrm{m} \\
\text { for } 24,28 \text {, and } 72 \text { hours of exposure }\end{array}$ & DNA damage \\
\hline Bhattacharya et al. [20] & $\begin{array}{c}\text { Bronchial cells } \\
\text { (human BEAS 2B) }\end{array}$ & $\begin{array}{l}\text { Toxicity of } \mathrm{TiO}_{2} \text { particles in anatase crystal } \\
\text { phase (size: }<100 \mathrm{~nm} \text { ) }\end{array}$ & $\begin{array}{l}\text { Reactive oxygen species (ROS) } \\
\text { production; DNA adduct formation }\end{array}$ \\
\hline Bhattacharya et al. [20] & $\begin{array}{l}\text { Lung fibroblast cells } \\
\text { (IMR-90) }\end{array}$ & $\begin{array}{l}\text { Toxicity of } \mathrm{TiO}_{2} \text { particles in anatase crystal } \\
\text { phase (size: }<100 \mathrm{~nm} \text { ) }\end{array}$ & Cytotoxicity \\
\hline
\end{tabular}

in vitro studies to in vivo studies. In this direction, some studies have used an endpoint that can be easily compared in in vitro and in vivo toxicity studies. For example, Faux et al. [119] used pulmonary inflammation as a response function for toxicity to epithelial cells in the centriacinar region of the lungs and in a petri dish. They reported that in vivo response (i.e., an increase in polymorphonuclear leukocytes in bronchoalveolar lavage fluid from rats) and in vitro response (i.e., an increase in inflammatory cytokine interleukin-8 mRNA in human alveolar epithelial cell line A549) were found to 
be comparable. More studies are required to explore this approach which can increase the usefulness of in vitro studies in the interest of time and cost.

On the other hand, recent studies are also considering the prospects of using alternative test methods to understand health risk and toxic effects of different chemicals. For example, the U.S. National Research Council's report [120] focuses on toxicity of chemicals to humans and suggests using alternative test methods to improve understanding. Studies are exploring suitability of alternative test methods (high throughput systems, in silico and in vitro models) for screening large number of samples containing ENMs and for reducing increased burden on animal testing $[41,43,120]$. For example, Frater et al. [41] applied predictive modelling and in vitro modelling for selecting carbon nanotubes in short-term inhalation or instillation studies. Similarly, Puzyn et al. [121] used experimental testing and quantum-mechanics-based computational modeling for studying cytotoxicity of metal oxide nanoparticles to $E$. coli. These recent efforts indicate the feasibility of using alternative test methods for toxicity studies in order to obtain data relevant to the dose-response step. These methods have also been mentioned in European Parliament and Council directives $[122,123]$. However, more efforts are clearly needed to improve toxicity screening of increasing number of nanomaterials.

\subsection{Effect of Physiochemical Characteristics of ENMs on} Toxicity. Physical and chemical properties of the ENMs have been shown to influence their toxicity [124-127]. There is currently a need for additional data providing information on the effects of ENMs characteristics (i.e., size, shape, chemical composition, and degree of agglomeration) on their toxicity [44]. ENM size in the environment depends on media characteristics. For example, ENM size in water depends on water physicochemical characteristics, such as ionic strength, $\mathrm{pH}$ solution, and presence of other co-ions [128]. Therefore the size of the ENMs needs to be determined in the exposure media and this needs to be related to the results from the hazard studies. Some studies have assessed the effect of size on ENM-induced toxicities to determine size-dependent dose-response model of ENMs for a given endpoint. For example, Falck et al. [56] observed that the lowest dose inducing DNA damage on bronchial cells BEAS $2 B$ is $1 \mu \mathrm{g} / \mathrm{cm}^{2}$ for fine rutile, $10 \mu \mathrm{g} / \mathrm{cm}^{2}$ for nanoanatase, and $80 \mu \mathrm{g} / \mathrm{cm}^{2}$ for nanorutile (see Table 2). Furthermore, particle size also affects extent of deposition in lungs during inhalation and its subsequent deposition in lungs and other organs as noted in Table 3 [44, 124]. For example, clearance of nanoparticles was found to be smaller than that of larger particles during inhalation exposure [124-126]. The finding of the Falck et al. [56] study also indicated the effect of crystallinity of nanoparticles on lowest dose inducing DNA damage. Further, chemical composition of ENMs also affects the extent of their toxicity [29]. For example, extent of toxicity of $\mathrm{TiO}_{2}$ and $\mathrm{Ag}$ nanoparticles differ for a given media. This information highlights the effects of size, shape, phase, and chemical composition on toxicity of ENMs and indicates a need for incorporating these factors into estimating the
ENM-based toxicity reference limits for animal and human exposure.

5.3. Nanomaterials Cooccurrence. There exists a possibility of cooccurrence of ENMs in the environment, indicating a chance of exposure to different types of ENMs simultaneously. To estimate human health risks due to exposure of more than one type of ENM in the environment, related toxicity data are required. Although data on exposure of individual ENMs to animals and human cell lines are available, data are still lacking on the effect of interaction with other chemicals and any possible subsequent synergistic or antagonistic effects on different target organs/organisms [40]. For example, Gou et al. [129] noted that synergism between the ENMs made of $\mathrm{Ag}$ and $\mathrm{TiO}_{2}$ is plausible on bacteria. As this study was conducted on bacteria, the obtained information about interaction of $\mathrm{Ag}$ and $\mathrm{TiO}_{2}$ particles cannot be used in EHHRA. To properly incorporate exposure of more than one type of ENM, information about cooccurrence of different ENMs in a given medium, chances of exposure of more than one type of ENM from a given exposure medium, and data on toxicity due to mixture of ENMs for a given target organ are required. For example, carbon nanotubes and fullerenes are emitted into the environment during combustion processes and coexist in air [130]. Both of these carbon-based ENMs affect alveoli region of lungs. A review by Aschberger et al. [131] indicates that toxicity studies are available only for carbon nanotubes or for fullerenes. However, these two types of carbon-based nanomaterials have not been studied together in toxicity studies. The information about effects of possible interactions of two or more than two ENMs on a given target organ need to be gathered to determine resultant dose-response curves.

Currently, the conventional approach is to develop doseresponse curves for a given endpoint using exposure of single type of contaminant. To account for toxicity due to cooccurring ENMs, one simplified approach could be to use reference values of exposure of single ENMs to target organ without assuming interaction with the other types of ENMs. It is similar to the USEPA's dose-addition-based risk assessment methodology [46, 132]. This methodology assumes that contaminants in mixture behaves similarly to how they would behave if they were present individually in water $[45,46]$. However, this approach might not capture the realistic effect of action on site, and two or more ENMs might be affecting. Towards this, the first attempt could be made by calculating the USEPA's interaction-based hazard index (HI), as seen in (1) $[46,132]$, for a mixture of ENMs. The $\mathrm{HI}$ is generally used for chemicals. In (1), $\mathrm{HQ}_{i}$ is hazard quotient for $i$ th chemical; $f_{i j}$ is toxic hazard of the $j$ th chemical relative to the total hazard from all chemicals potentially interacting with $i$ th chemical. The magnitude of interaction between chemicals is represented by $M_{i j}$ (an interaction magnitude parameter, default value $=5[46]$ ) The strength of evidence that $i$ th chemical influences the toxicity of $j$ th chemical is represented by $B_{i j}$ (i.e., weight-ofevidence factor (2a)). Also, $g_{i j}$ in (1) indicates a degree to which $i$ th chemical and $j$ th chemical are present in equitoxic amounts (2b). For the case of two chemicals, $f$ value is 
1 as $\mathrm{HQ}_{12}=\mathrm{HQ}_{2} /\left[\mathrm{HI}_{\mathrm{add}}-\mathrm{HQ}_{1}\right]=\mathrm{HQ}_{2} /\left[\mathrm{HQ}_{2}\right] . B$ can be assigned to default value of 0.5 based on guidelines from the USEPA [46] methodology, as also used by studies elsewhere $[133,134]$.

$$
\begin{gathered}
\mathrm{HI}_{\mathrm{int}}=\sum_{i=1}^{n} \mathrm{HQ}_{i} \sum_{j \neq i}^{n}\left(f_{i j} \times M_{i j}{ }^{B_{i j} \times g_{i j}}\right) . \\
f_{i j}=\frac{\mathrm{HQ}_{j}}{\mathrm{HI}_{\mathrm{add}}-\mathrm{HQ}_{i}} \\
g_{i j}=\frac{\sqrt{\mathrm{HQ}_{i} \times \mathrm{HQ}_{j}}}{0.5 \times\left(\mathrm{HQ}_{i}+\mathrm{HQ}_{j}\right)} .
\end{gathered}
$$

The USEPA's risk assessment methodology for chemicals for estimating risks can only be used for estimating risks due to exposure of mixture of ENMs provided this equation holds true for ENMs mixture as well. Currently, not much work has been conducted to understand applicability of (1) and $((2 a)$ and $(2 b))$ in this regard. The first step towards this approach is to gather information about all parameters used in these two equations. The following steps are encouraged to modify current ENM-related occurrence and toxicity studies: (i) calculate the chance of cooccurrence of different ENMs in a given medium, (ii) develop groups of cooccurring ENMs influencing a given endpoint, and (iii) obtain dose-response data during simultaneous exposure of two or more ENMs to target models under study if available or conduct studies to obtain these data to assess the effect of cooccurrence of ENMs on toxicity endpoints. Using this additional information, the USEPA methodology for mixture of chemicals ((1), (2a) and (2b)) may be applied to estimate risks due to exposure of ENMs, until detailed methodology for mixture of ENMs is available.

\subsection{Fate of ENMs in Organisms and Translocation Assessment.} Inhaled or ingested ENMs could be translocated to different parts of the body through systemic distribution [135]. As a result, the exposure of ENMs from one particular route might result in exposure of ENMs to different organs. Thus, exposure assessment and dose-response assessment stages need to consider this aspect for assessing overall toxicity from a given exposure route.

During inhalation exposure, ENMs may deposit in lungs where they may disaggregate into smaller particles in the alveolar lining fluid, resulting in exposure of both nanosize and micron-size particles to interior parts of the lungs [136]. Once particles are deposited in the respiratory tract, clearance mechanisms such as mucociliary clearance in airways or alveolar macrophage-mediated clearance in gas-exchange region govern deposition, clearance, and translocation of particles to other regions [124-126]. This translocation happens when particles enter in the lymph or blood circulation. Thus, the ENMs exposed through inhalation route reach to lungs as well as in other organs.

Similar observations have been found in the case of oral exposure of ENMs. For example, the biodistribution experiment by Wang et al. [137] on adult mice showed that orally administered $\mathrm{TiO}_{2}$ was found to be retained mainly in the liver, spleen, kidneys, and lung tissues, indicating translocation of $\mathrm{TiO}_{2}$ particles to other tissues and organs after uptake by gastrointestinal tract. The work of Park et al. [138] reported that, when mice were orally treated with $1 \mathrm{mg} / \mathrm{kg}$ Ag particles for 14 days, small-sized Ag particles ( $22 \mathrm{~nm}, 42 \mathrm{~nm}$, and $71 \mathrm{~nm}$ ) were found to be distributed to brain, lung, liver, kidney, and testis. However, large-sized Ag particles $(323 \mathrm{~nm})$ were not detected in these organ tissues, indicating an effect of size on translocation. Furthermore, a recent study by van der Zande et al. [139] noticed in vivo formation of silver nanoparticles in rat organs during their oral exposure to silver salts over a study duration of 28 days. These findings indicate the possibility of in vivo formation of nanoparticles, which also needs to be considered in estimating exposure dose of nanoparticles in risk assessment process.

5.5. Toxicity Study Duration. Although data from acute- or subchronic studies on animal toxicity studies $[13,140]$ are available, they do not represent fully the toxicity of ENMs to target organs during long-term exposure. Thus, uncertainty on extrapolation from subchronic to chronic exposure data still exists. As chronic studies are expensive, there is a need for developing short-term tests to simulate chronic exposure scenario. In these studies, biological indictors whose response can be extended based on causal relationship for long-term exposure need to be explored in detail [44]. In addition, there could be differences in toxicodynamics and toxicokinetic response in short- and long-term studies during the use of low concentration of ENMs, which need to be considered in these short-term tests. Overall, there is a need for conducting more long-term toxicity studies or combining experimental data [29] and simulation-based hybrid approach to predict long-term toxicity effects.

\subsection{Quantitative Nanostructure-Toxicity Relationship} (QNTR). Quantitative structure-activity relationship (QSAR) has been widely used in pharmacology and related fields to predict the toxicity of drugs without the need for tedious, time-consuming, and expensive animal testing. An analogue of the model, QNTR, has been extended to nanomaterials. In this context, Winkler et al. [141] recently noted that structural properties of nanomaterials, which influence toxicity, may include size, shape, surface area, and degree of electrostatic interaction between nanomaterials and their cellular environments as well as other physicochemical properties of nanomaterials. These properties have been used as descriptors $[121,141,142]$ for the prediction of the properties of new materials or for the explaining of their biological effects. In many instances, such predictions are facilitated by the use of multivariate data analysis techniques including regression models and artificial neural networks and verified by cross-validation, using training and validation data sets [143].

Emerging results from these types of studies indicate that the structural properties, which influence the toxicity of nanomaterials, can reside both in the core and on the 
surface of the materials $[141,144]$. However, to extend QSAR to QNTR effectively, a number of challenges need to be addressed. Winkler et al. [141] have mentioned some of these challenges as

(i) lack of adequate definition and understanding of the biologically important entities that moderate the adverse effects of nanomaterials,

(ii) need to choose the right assays that can be used to model and correlate the toxic effects of nanomaterials in vitro and in vivo,

(iii) accurate modeling of the complex interactions between nanomaterials and biological systems,

(iv) understanding of the relationship between QNTR methods and other computational approaches such as quantum chemistry and molecular dynamics.

These challenges arise due to following data gaps: (i) lack of sufficient empirical data on the composition of biocorona on the surfaces of nanomaterials; (ii) lack of in vitro data that can be used to predict in vivo effects of nanomaterials, and (iii) the paucity of descriptors that can specifically be used for nanomaterials [141]. Despite these challenges and data gaps, progress has been made in probing and understanding the interactions of nanomaterials with their biological environments. For example, Lynch and Dawson [145] described the use, strengths, and shortcomings of surface plasmon resonance, magnetic nanosensor arrays, surface adsorption index, isothermal titration calorimetry, shotgun proteomics analysis, fluorescence correlation spectroscopy, size exclusion chromatography, and liquid chromatography-tandem mass spectrometry in increasing the understanding of the interaction of nanomaterials with environmental molecules.

However, the gaps in knowledge must be fully identified and understood before an internationally acceptable approach to QNTR is proposed, which can appeal to all stakeholders. An important initiative taken towards achieving this goal was captured by a recent workshop (http://www.cost.eu/events/qntr) on the use of QNTR methods in modelling the biological effects of nanomaterials. This workshop highlighted the challenges envisaged and the proposed methods of overcoming these challenges. It also proposed short- to long-term steps that could be taken to address the challenges (Table 4). In a similar development, Stone et al. [43] reported that a European Commission funded a project, which was undertaken to identify the framework of future research priorities for the development of an intelligent testing strategy (ITS) for evaluating nanomaterials safety without the need for caseby-case assessment of human and environmental exposure. Some short-, medium-, and long-term research priorities emanating from the project are also included in Table 4. Readers interested in the full report are encouraged to visit http://www.nano.hw.ac.uk/research-projects/itsnano.html [43].

\section{Environmental Regulations of ENMs}

A review of literature indicates that not much information is available on the regulation of ENM-related exposure $[8,67]$. The scope of different available regulations and guidelines in the USA, European Union, and WHO is limited to organic compounds and toxic substances, but they do not specifically address ENM-related pollution. Air quality directives set by the US Environmental Protection Agency (USEPA) and the European Commission (EC) include concentration limits for particulate pollution [146, 147]. These limits, however, refer to mass concentration measurements (i.e., $\mathrm{PM}_{10}$ and $\mathrm{PM}_{2.5}$ ), which are not appropriate for airborne nanoparticles $[75,148]$. Some studies have attempted to understand the suitability of current regulations in handling ENM pollution. For example, Beaudrie et al. [110] analysed U.S. Federal Environmental, Health, and Safety (EHS) regulations for their adequacy and application to ENMs using a life-cycle framework. They found that existing regulations for controlling occupational exposure and environmental pollution (e.g., the OSHA Act, the Clean Air Act, and the Clean Water Act) do not provide provisions for addressing regulation of ENM-related environmental pollution. Finding of this study indicated that there is a need for investigating suitability of current regulations for controlling environmental pollution of ENMs. As the development of environmental regulation for ENMs is still undergoing, regulatory bodies of some countries such as the US [95], UK [41, 120], and Australia [62, 63] are investigating if ENM-based products could be treated as new classes of existing substances, which are currently being regulated. Towards this, many countries have started collecting nanospecific data from each product and building a database so that it can be used in regulating ENMs. For example, the US is collecting substance-specific information for ENMs from different products for regulating ENMs [149]. It appears that regulatory bodies may continue to use existing regulations to address ENM pollution until ENM-related regulation is structured and approved. In this regard, some studies have suggested communication of nanospecific information of products to all stakeholders (manufacturers, users, and regulatory bodies) in an effective manner. For example, Nowack et al. [150] analysed release and behaviour of ENMs for the context of major accident prevention and suggested to include nanospecific data in material safety data sheets on a compulsory basis. Furthermore, a notable amount of current research is focusing on prioritising ENM-related research issues and exposure metrics to develop stakeholder-driven intelligent testing methods and strategies. For example, recent work of Stone et al. [43] used opinions of experts from government, academia, industry, funders, and NGOs for systematically identifying a need for information in the areas of physicochemical characterisation, exposure identification, and hazard identification and modelling approaches for short-, medium-, and long-term time scales. There is clearly a need for initiating regulatory efforts to develop guidelines and monitoring metrics for regulating the presence of ENMs in water, air, and soil media. Whether these limits should be 
TABLE 4: Desirable (achievable) outcomes of quantitative nanostructure-toxicity relationship (QNTR) in the next ten years adapted from published studies (Winkler et al. [141]; Stone et al. [43]).

\begin{tabular}{lll}
\hline Short-term & Medium-term & Long-term \\
$\begin{array}{l}\text { (i) Fully characterised nanomaterials that can } \\
\text { be used in experiments }\end{array}$ & $\begin{array}{l}\text { (i) Appreciable data on in vivo effects } \\
\text { of nanomaterials } \\
\text { (ii) Robust in vivo models for } \\
\text { predicting the endpoints of } \\
\text { nanomaterials interaction with } \\
\text { biological systems }\end{array}$ & $\begin{array}{l}\text { (i) Sufficient in vitro and in vivo information on } \\
\text { nanomaterials to assist the development of } \\
\text { regulatory measures }\end{array}$ \\
$\begin{array}{ll}\text { (ii) In vitro assays that are useful for the } \\
\text { assessment of toxicologically relevant effects }\end{array}$ & $\begin{array}{l}\text { (ii) Reliable models for prediction and } \\
\text { risk-based classification of nanomaterials }\end{array}$ \\
$\begin{array}{ll}\text { (iii) Fast and highly efficient methods for } \\
\text { measuring and modelling the interaction of } \\
\text { nanomaterials with biological systems }\end{array}$ & $\begin{array}{l}\text { (iii) In-depth understanding of the } \\
\text { mechanism of nanomaterials toxicity }\end{array}$ & $\begin{array}{l}\text { (iii) Integration of the data into legal } \\
\text { framework, life-cycle assessment, and decision } \\
\text { trees }\end{array}$ \\
$\begin{array}{l}\text { (iv) Specific descriptors for modelling the } \\
\text { relationships among the structures and } \\
\text { toxicity properties of nanomaterials }\end{array}$ & $\begin{array}{l}\text { (iv) Information on cohort and } \\
\text { population; direct and indirect; } \\
\text { short-/long-term reversible and } \\
\text { irreversible effects }\end{array}$ & $\begin{array}{l}\text { (iv) Implementation of risk assessment } \\
\text { frameworks }\end{array}$ \\
\hline
\end{tabular}

based on number, mass or surface area concentrations are still contentious [8].

\section{Summary, Conclusions, and Future Directions}

This article provides current status of knowledge in areas of measurements, characterisation, and environmental risk assessment of the ENMs besides identifying the research gaps and future directions. The proposed future steps could help in (i) providing information about monitoring of ENMs and dose-response parameters reflecting environmental exposure conditions, and (ii) developing QNTR. The summary and key conclusions on the topic areas covered are listed below.

(i) The field of ENM monitoring is yet fairly new and therefore the monitoring methods are generally adopted from the existing techniques for monitoring particle pollution in air and water environments. The greatest challenge in monitoring the concentration of ENMs in any environment is to distinguish them from the background nanomaterials.

(ii) Methods are available for measuring particle number concentration and characteristics. Particle concentration and size distribution can be measured using instruments such as DLS, CPC, DMPS, FMPS, ELPI, and SMPS. Surface characterisation of nanomaterials is generally conducted using SEM, TEM, EDX, BET, TG, FTIR, near-infrared, and Raman's spectroscopy methods. These methods are usually complicated, time-consuming, and expensive, thereby making them inappropriate for routine monitoring of ENMs in different environmental media.

(iii) Current toxicity studies do not use realistic exposure conditions during dose-response experiments and hence these are inappropriate for the EHHRA of ENMs. In addition, recent studies have started developing relationships between structural properties of nanomaterials and toxicity (i.e., QNTR) for use in the dose-response step. However, this approach needs extensive empirical data on physicochemical characteristics and toxicity of ENMs. Such data are currently unavailable in abundance and need to be systematically obtained.

(iv) In order to address mixture toxicity issue in the EHHRA of ENMs, the following steps are proposed. (i) Calculate chances of cooccurrence of different ENMs in a given medium. (ii) Develop groups of cooccurring ENMs influencing a given endpoint. (iii) Obtain dose-response data during simultaneous exposure of two or more ENMs to target cell line or target organ or animal used in toxicity studies. And (iv) use the USEPA methodology for mixture of chemicals for conducting risk estimation of exposure of ENMs until detailed methodology for mixture of ENMs is available. These steps need to be pursued for investigating their appropriateness in assessing health risks due to exposure to ENMs.

(v) Despite increased awareness in public and recent reporting of ENMs in environment, not much information is yet available to regulate them due to the continuing technical difficulties.

Figure 1 presents the interlinking of identified factors affecting the EHHRA of ENMs. The following directions for future research works can assist in filling the research gaps on the topic areas covered:

(i) developing a combination of different analytical methods for determining ENM mass concentration, particle concentration, and morphological information,

(ii) conducting toxicity studies using conditions relevant to environmental exposure of ENMs for humans to obtain dose-response information useful in EHHRA of ENMs,

(iii) obtaining relevant data in order to develop QNTR relationships, 


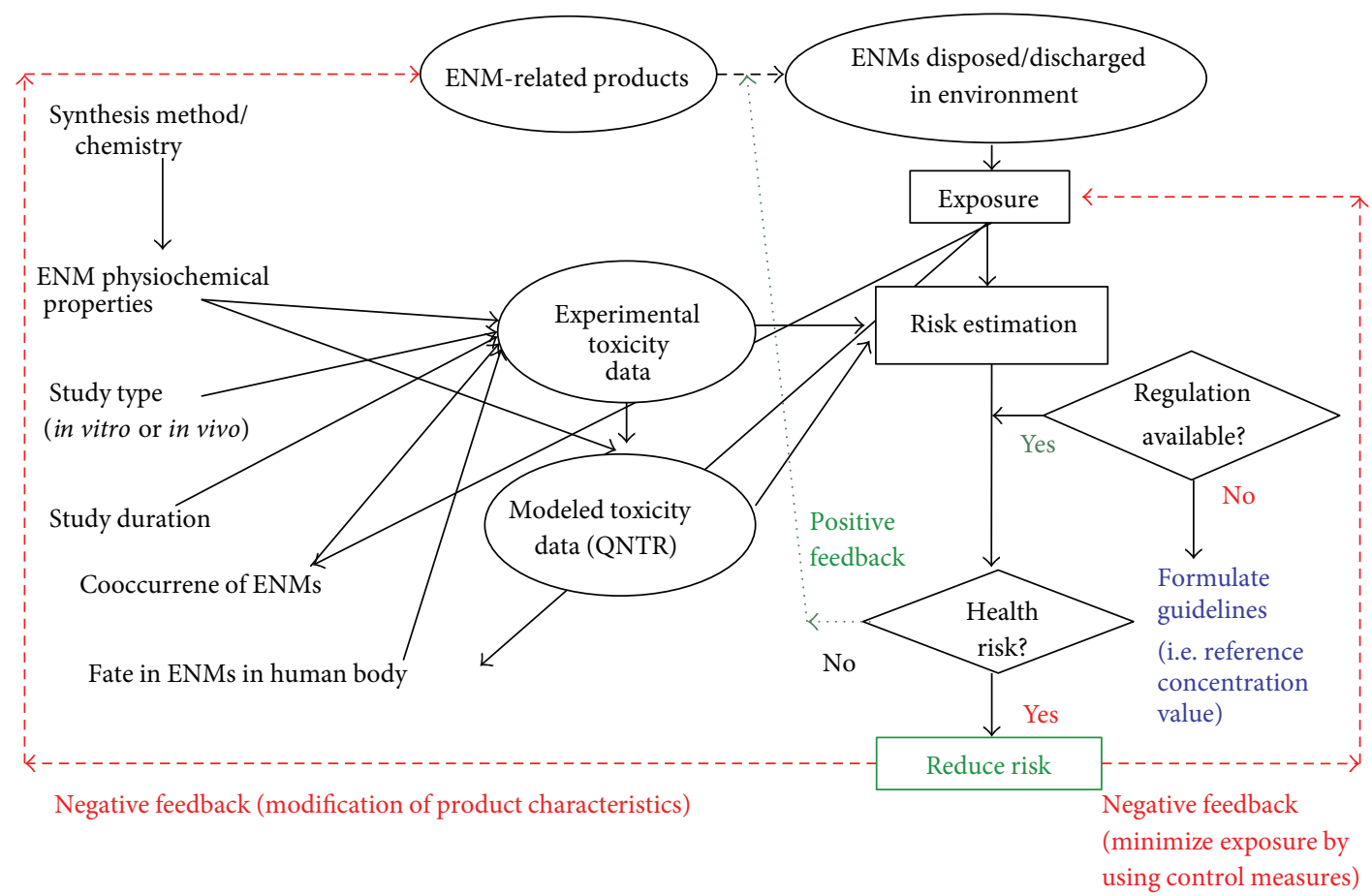

FIGURE 1: Schematic showing interlinkages of different factors for determining environmental and health risks due to ENM exposure.

(iv) initiating efforts for formulating guidelines for regulating presence of ENMs in different environmental media.

\section{Conflict of Interests}

The authors declare that there is no conflict of interests regarding the publication of this paper.

\section{Acknowledgments}

Arun Kumar thanks the IIT Delhi and the Department of Science and Technology, India (Grant no. DST/TM/WTI/ 2K11/301) for the funding support. Prashant Kumar greatly acknowledges the EPSRC and Surrey University for the student support and instrument research grants. Except otherwise indicated, the views expressed in this paper are those of the authors.

\section{References}

[1] M. C. Roco and W. S. Bainbridge, "Societal implications of nanoscience and nanotechnology," in Nanoscale, Sceince, Engineering and Technology (NSET) Workshop Report, p. 280, Springer (Formerly Kluwer) Publications, 2001, http://www .wtec.org/loyola/nano/NSET.Societal.Implications/nanosi.pdf.

[2] A. D. Maynard and E. D. Kuempel, "Airborne nanostructured particles and occupational health," Journal of Nanoparticle Research, vol. 7, no. 6, pp. 587-614, 2005.

[3] N. C. Mueller and B. Nowack, "Exposure modeling of engineered nanoparticles in the environment," Environmental Science \& Technology, vol. 42, no. 12, pp. 4447-4453, 2008.
[4] H. P. Jarvie, H. Al-Obaidi, S. M. King et al., "Fate of silica nanoparticles in simulated primary wastewater treatment," Environmental Science \& Technology, vol. 43, no. 22, pp. 86228628, 2009.

[5] T. Xia, N. Li, and A. E. Nel, "Potential health impact of nanoparticles," Annual Review of Public Health, vol. 30, pp. 137150, 2009.

[6] F. Gottschalk, T. Sonderer, R. W. Scholz, and B. Nowack, "Modeled environmental concentrations of engineered nanomaterials $\left(\mathrm{TiO}_{2}, \mathrm{ZnO}, \mathrm{Ag}, \mathrm{CNT}\right.$, fullerenes) for different regions," Environmental Science \& Technology, vol. 43, no. 24, pp. 92169222, 2009.

[7] D. Brouwer, "Exposure to manufactured nanoparticles in different workplaces," Toxicology, vol. 269, no. 2-3, pp. 120-127, 2010.

[8] P. Kumar, P. Fennell, and A. Robins, "Comparison of the behaviour of manufactured and other airborne nanoparticles and the consequences for prioritising research and regulation activities," Journal of Nanoparticle Research, vol. 12, no. 5, pp. 1523-1530, 2010.

[9] P. Kumar and A. N. Al-Dabbous, "Emission, transformation and fate of nanoparticles in the atmosphere," in Engineered Nanoparticles and the Environment: Biophysicochemical Processes and Biotoxicity, N. Senesi, Ed., vol. 4 of IUPAC-Sponsored Wiley Book Series, 2014.

[10] C.-W. Lam, J. T. James, R. McCluskey, S. Arepalli, and R. L. Hunter, "A review of carbon nanotube toxicity and assessment of potential occupational and environmental health risks," Critical Reviews in Toxicology, vol. 36, no. 3, pp. 189-217, 2006.

[11] D. Dankovic, E. Kuempel, and M. Wheeler, "An approach to risk assessment for $\mathrm{TiO}_{2}$," Inhalation Toxicology, vol. 19, no. 1, pp. 205-212, 2007.

[12] C.-M. Liao, Y.-H. Chiang, and C.-P. Chio, "Model-based assessment for human inhalation exposure risk to airborne nano/fine 
titanium dioxide particles," Science of the Total Environment, vol. 407, no. 1, pp. 165-177, 2008.

[13] B. Trouiller, R. Reliene, A. Westbrook, P. Solaimani, and R. H. Schiestl, "Titanium dioxide nanoparticles induce DNA damage and genetic instability in vivo in mice," Cancer Research, vol. 69, no. 22, pp. 8784-8789, 2009.

[14] G. Biskos and A. Schmidt-Ott, "Airborne engineered nanoparticles: potential risks and monitoring challenges for assessing their impacts on children," Paediatric Respiratory Reviews, vol. 13, no. 2, pp. 79-83, 2012.

[15] Y. Morimoto, N. Kobayashi, N. Shinohara, T. Myojo, I. Tanaka, and J. Nakanishi, "Hazard assessments of manufactured nanomaterials," Journal of Occupational Health, vol. 52, no. 6, pp. 325-334, 2010.

[16] B. Nowack and T. D. Bucheli, "Occurrence, behavior and effects of nanoparticles in the environment," Environmental Pollution, vol. 150, no. 1, pp. 5-22, 2007.

[17] C. A. Poland, R. Duffin, I. Kinloch et al., "Carbon nanotubes introduced into the abdominal cavity of mice show asbestoslike pathogenicity in a pilot study," Nature Nanotechnology, vol. 3, no. 7, pp. 423-428, 2008.

[18] J. P. Ryman-Rasmussen, J. E. Riviere, and N. A. MonteiroRiviere, "Penetration of intact skin by quantum dots with diverse physicochemical properties," Toxicological Sciences, vol. 91, no. 1, pp. 159-165, 2006.

[19] D. W. Porter, A. F. Hubbs, R. R. Mercer et al., "Mouse pulmonary dose- and time course-responses induced by exposure to multiwalled carbon nanotubes," Toxicology, vol. 269, no. 2-3, pp. 136$147,2010$.

[20] K. Bhattacharya, M. Davoren, J. Boertz, R. P. F. Schins, E. Hoffmann, and E. Dopp, "Titanium dioxide nanoparticles induce oxidative stress and DNA-adduct formation but not DNAbreakage in human lung cells," Particle and Fibre Toxicology, vol. 6, article 17, 2009.

[21] K. Morgan, "Development of a preliminary framework for informing the risk analysis and risk management of nanoparticles," Risk Analysis, vol. 25, no. 6, pp. 1621-1635, 2005.

[22] M. R. Wiesner, G. V. Lowry, P. Alvarez, D. Dionysiou, and P. Biswas, "Assessing the risks of manufactured nanomaterials," Environmental Science \& Technology, vol. 40, no. 14, pp. 43364345, 2006.

[23] J. S. Tsuji, A. D. Maynard, P. C. Howard et al., "Research strategies for safety evaluation of nanomaterials, part IV: risk assessment of nanoparticles," Toxicological Sciences, vol. 89, no. 1, pp. 42-50, 2006.

[24] M. Kandlikar, G. Ramachandran, A. Maynard, B. Murdock, and W. A. Toscano, "Health risk assessment for nanoparticles: a case for using expert judgment," Journal of Nanoparticle Research, vol. 9, no. 1, pp. 137-156, 2007.

[25] A. Kroll, M. H. Pillukat, D. Hahn, and J. Schnekenburger, "Current in vitro methods in nanoparticle risk assessment: limitations and challenges," European Journal of Pharmaceutics and Biopharmaceutics, vol. 72, no. 2, pp. 370-377, 2009.

[26] N. Shinohara, M. Gamo, and J. Nakanishi, "Risk assessment of manufactured nanomaterials-fullerene (C60)," Interim Report, Executive Summary, NEDO Project-Research and Development of Nanoparticle Characterization Methods, P06041, 2009.

[27] G. L. Baker, A. Gupta, M. L. Clark et al., "Inhalation toxicity and lung toxicokinetics of $\mathrm{C}_{60}$ fullerene nanopaticles and microparticles," Toxicological Sciences, vol.101, no. 1, pp. 122-131, 2008.
[28] T. Tervonen, I. Linkov, J. R. Figueira, J. Steevens, M. Chappell, and M. Merad, "Risk-based classification system of nanomaterials," Journal of Nanoparticle Research, vol. 11, no. 4, pp. 757-766, 2009.

[29] N. O'Brien and E. Cummins, "Development of a three-level risk assessment strategy for nanomaterials," in Nanomaterials: Risks and Benefits, I. Linkov and J. Steevens, Eds., pp. 161-178, Springer, The Netherlands, 2009.

[30] K. D. Grieger, A. Baun, and R. Owen, "Redefining risk research priorities for nanomaterials," Journal of Nanoparticle Research, vol. 12, no. 2, pp. 383-392, 2010.

[31] F. M. Christensen, H. J. Johnston, V. Stone et al., "Nano-silverfeasibility and challenges for human health risk assessment based on open literature," Nanotoxicology, vol. 4, no. 3, pp. 284295, 2010.

[32] F. M. Christensen, H. J. Johnston, V. Stone et al., "Nano- $\mathrm{TiO}_{2}-$ easibility and challenges for human health risk assessment based on open literature," Nanotoxicology, vol. 5, no. 2, pp. 110124, 2011.

[33] S. Gangwal, J. S. Brown, A. Wang et al., "Informing selection of nanomaterial concentrations for ToxCast in vitro testing based on occupational exposure potential," Environmental Health Perspectives, vol. 119, no. 11, pp. 1539-1546, 2011.

[34] A. Anandan and A. Kumar, "Exposures to $\mathrm{TiO}_{2}$ and Ag nanoparticles: what are human health risks?" Science and Society, vol. 9, no. 2, pp. 155-162, 2011.

[35] A. C. Johnson, M. J. Bowes, A. Crossley et al., "An assessment of the fate, behaviour and environmental risk associated with sunscreen $\mathrm{TiO}_{2}$ nanoparticles in UK field scenarios," Science of the Total Environment, vol. 409, no. 13, pp. 2503-2510, 2011.

[36] P. Kumar, B. R. Gurjar, A. S. Nagpure, and R. M. Harrison, "Preliminary estimates of nanoparticle number emissions from road vehicles in megacity Delhi and associated health impacts," Environmental Science \& Technology, vol. 45, no. 13, pp. 55145521, 2011.

[37] A. Kumar, "Making a case for human health risk-based ranking of nanoparticles in water for monitoring purposes," Environmental Science \& Technology, vol. 46, no. 10, pp. 5267-5268, 2012.

[38] P. Kumar, A. Kumar, and J. R. Lead, "Nanoparticles in the Indian environment: known, unknowns and awareness," Environmental Science \& Technology, vol. 46, no. 13, pp. 7071-7072, 2012.

[39] D. Singh and A. Kumar, "Identifying knowledge gaps in assessing health risks due to exposures of nanoparticles from contaminated edible plants," in Management of Water, Energy and Bio-Resources in the Era of Climate Change: Emerging Issues and Challenges, pp. 229-242, Springer, 2014.

[40] I. Khanna and A. Kumar, "Including nanoparticles mixtures in human health risk assessment," Integrated Environmental Assessment and Management, vol. 10, no. 1, p. 144, 2014.

[41] L. Frater, E. Stokes, R. Lee, and T. Oriola, An Overview of the Framework of Current Regulation Affecting the Development and Marketing of Nanomaterials, ESRC Centre for Business RelationshipsAccountability Sustainability and Society (BRASS), Cardiff University:, Cardiff, UK, 2006, http://www.berr.gov.uk/ files/file36167.pdf.

[42] K. Savolainen, U. Backman, D. Brouwer et al., Nanosafety in Europe 2015-2025: Towards Safe and Sustainable Nanomaterials and Nanotechnology Innovations, Finnish Institute of Occupational Health, 2013.

[43] V. Stone, S. Pozzi-Mucelli, L. Tran et al., "ITS-NANOprioritising nanosafety research to develop a stakeholder driven 
intelligent testing strategy," Particle and Fibre Toxicology, vol. 11, article 9, 2014.

[44] E. Kuempel, C. Tran, V. Castranova, and A. Bailer, "Lung dosimetry and risk assessment of nanoparticles: evaluating and extending current models in rats and humans," Inhalation Toxicology, vol. 18, no. 10, pp. 717-724, 2006.

[45] USEPA, "Guidelines for health risk assessment of chemical mixtures," Federal Register, vol. 51, no. 185, pp. 34014-34025, 1986.

[46] USEPA, "Supplementary guidance for conducting health risk assessment of chemical mixtures," EPA/630/R-00/002 Cincinnati, Ohio, USA, ORD/NCEA, 2000.

[47] O. A. Sadik, "Anthropogenic nanoparticles in the environment," Environmental Science: Processes \& Impacts, vol. 15, pp. 19-20, 2013.

[48] O. A. Sadik, A. L. Zhou, S. Kikandi, N. Du, Q. Wang, and K. Varner, "Sensors as tools for quantitation, nanotoxicity and nanomonitoring assessment of engineered nanomaterials," Journal of Environmental Monitoring, vol. 11, no. 10, pp. 17821800, 2009.

[49] A. J. Koster, U. Ziese, A. J. Verkleij, A. H. Janssen, and K. P. De Jong, "Three-dimensional transmission electron microscopy: a novel imaging and characterization technique with nanometer scale resolution for materials science," Journal of Physical Chemistry B, vol. 104, no. 40, pp. 9368-9370, 2000.

[50] P. Kumar, A. Robins, S. Vardoulakis, and R. Britter, "A review of the characteristics of nanoparticles in the urban atmosphere and the prospects for developing regulatory controls," Atmospheric Environment, vol. 44, no. 39, pp. 5035-5052, 2010.

[51] L. Morawska, H. Wang, Z. Ristovski et al., "JEM spotlight: environmental monitoring of airborne nanoparticles," Journal of Environmental Monitoring, vol. 11, no. 10, pp. 1758-1773, 2009.

[52] M. Kruk and M. Jaroniec, "Gas adsorption characterization of ordered organic-inorganic nanocomposite materials," Chemistry of Materials, vol. 13, no. 10, pp. 3169-3183, 2001.

[53] M. V. Borrachero, J. Payá, M. Bonilla, and J. Monzó, “The use of thermogravimetric analysis technique for the characterization of construction materials: the gypsum case," Journal of Thermal Analysis and Calorimetry, vol. 91, no. 2, pp. 503-509, 2008.

[54] A. López-Lorente, B. M. Simonet, and M. Valcárcel, "Raman spectroscopic characterization of single walled carbon nanotubes: influence of the sample aggregation state," Analyst, vol. 139, pp. 290-298, 2014.

[55] J. Gaury, E. M. Kelder, E. Bychkov, and G. Biskos, "Characterization of Nb-doped WO3 thin films produced by Electrostatic Spray Deposition," Thin Solid Films, vol. 534, pp. 32-39, 2013.

[56] G. C. M. Falck, H. K. Lindberg, S. Suhonen et al., "Genotoxic effects of nanosized and fine $\mathrm{TiO}_{2}$," Human and Experimental Toxicology, vol. 28, no. 6-7, pp. 339-352, 2009.

[57] J. Chapman, T. Sullivan, and F. Regan, "Nanoparticles: what are they?" in Nanoparticles in Anti-Microbial Materials: Use and Characterization, RSC Nanoscience \& Nanotechnology No. 23, chapter 1, Royal Society of Chemistry, 2012.

[58] H. Goesmann and C. Feldmann, "Nanoparticulate functional materials," Angewandte Chemie International Edition, vol. 49, no. 8, pp. 1362-1395, 2010.

[59] G. Oberdörster, A. Maynard, K. Donaldson et al., "Principles for characterizing the potential human health effects from exposure to nanomaterials: elements of a screening strategy," Particle and Fibre Toxicology, vol. 2, article 8, pp. 1-35, 2005.
[60] P. Kumar, A. Robins, and H. Apsimon, "Nanoparticle emissions from biofuelled vehicles-their characteristics and impact on the number-based regulation of atmospheric particles," Atmospheric Science Letters, vol. 11, no. 4, pp. 327-331, 2010.

[61] P. Kumar, A. Robins, S. Vardoulakis, and P. Quincey, “Technical challenges in tackling regulatory concerns for urban atmospheric nanoparticles," Particuology, vol. 9, no. 6, pp. 566-571, 2011.

[62] D. M. Bowman and G. A. Hodge, "Nanotechnology: mapping the wild regulatory frontier," Futures, vol. 38, no. 9, pp. 10601073, 2006.

[63] K. Ludlow, D. Bowman, and G. Hodge, A Review of Possible Impacts of Nanotechnology on Australia's Regulatory Framework, Monash Centre for Regulatory Studies, Monash University, Melbourn, Australia, 2007, http://www.innovation.gov.au/ Industry/Nanotechnology/NationalEnablingTechnologiesStrategy/Documents//MonashReport2007.pdf.

[64] A. N. Al-Dabbous and P. Kumar, "The influence of roadside vegetation barriers on airborne nanoparticles and pedestrians exposure under varying wind conditions," Atmospheric Environment, vol. 90, pp. 113-124, 2014.

[65] P. Kumar, M. Mulheron, B. Fisher, and R. M. Harrison, "New directions: airborne ultrafine particle dust from building activities-a source in need of quantification," Atmospheric Environment, vol. 56, pp. 262-264, 2012.

[66] P. Kumar, M. Mulheron, and C. Som, "Release of ultrafine particles from three simulated building processes," Journal of Nanoparticle Research, vol. 14, no. 4, article 0771, 2012.

[67] P. Kumar, L. Pirjola, M. Ketzel, and R. M. Harrison, "Nanoparticle emissions from 11 non-vehicle exhaust sources-a review," Atmospheric Environment, vol. 67, pp. 252-277, 2013.

[68] P. Kumar and L. Morawska, "Recycling concrete: an undiscovered source of ultrafine particles," Atmospheric Environment, vol. 90, pp. 51-58, 2014.

[69] P. Kumar, A. Robins, and R. Britter, "Fast response measurements of the dispersion of nanoparticles in a vehicle wake and a street canyon," Atmospheric Environment, vol. 43, no. 38, pp. 6110-6118, 2009.

[70] M. Carpentieri and P. Kumar, "Ground-fixed and on-board measurements of nanoparticles in the wake of a moving vehicle," Atmospheric Environment, vol. 45, no. 32, pp. 58375852, 2011.

[71] P. Joodatnia, P. Kumar, and A. Robins, "The behaviour of traffic produced nanoparticles in a car cabin and resulting exposure rates," Atmospheric Environment, vol. 65, pp. 40-51, 2013.

[72] P. Joodatnia, P. Kumar, and A. Robins, "Fast response sequential measurements and modelling of nanoparticles inside and outside a car cabin," Atmospheric Environment, vol. 71, pp. 364-375, 2013.

[73] R. Goyal, M. Khare, and P. Kumar, "Indoor air quality: current status, missing links and future road map for India," Journal of Environment and Civil Engineering, vol. 2, p. 118, 2012.

[74] R. Goyal and P. Kumar, "Indoor-outdoor concentrations of particulate matter in nine microenvironments of a mix-use commercial building in megacity Delhi," Air Quality, Atmosphere \& Health, vol. 6, no. 4, pp. 747-757, 2013.

[75] P. Kumar, M. Ketzel, S. Vardoulakis, L. Pirjola, and R. Britter, "Dynamics and dispersion modelling of nanoparticles from road traffic in the urban atmospheric environment-a review," Journal of Aerosol Science, vol. 42, no. 9, pp. 580-603, 2011. 
[76] J. K. Agarwal and G. J. Sem, "Continuous flow, single-particlecounting condensation nucleus counter," Journal of Aerosol Science, vol. 11, no. 4, pp. 343-357, 1980.

[77] P. H. McMurry, "A review of atmospheric aerosol measurements," Atmospheric Environment, vol. 34, no. 12-14, pp. 19591999, 2000.

[78] A. Schmidt-Ott and T. Kauffeldt, "Assessment of particulate air pollution by new sensor concepts," in Recent Developments in Measurement and Assessment of Air Pollution, vol. 1443, pp. 517528, V D I-V D E-Verlag Gmbh, Dusseldorf, Germany, 1999.

[79] G. Biskos, K. Reavell, and N. Collings, "Description and theoretical analysis of a differential mobility spectrometer," Aerosol Science and Technology, vol. 39, no. 6, pp. 527-541, 2005.

[80] G. Biskos, V. Vincent, C. U. Yurteri, and A. Schmidt-Ott, "Generation and sizing of particles for aerosol-based nanotechnology," Kona Powder and Particle Journal, vol. 26, pp. 13-35, 2008.

[81] E. O. Knutson and K. T. Whitby, "Aerosol classification by electric mobility: apparatus, theory, and applications," Journal of Aerosol Science, vol. 6, no. 6, pp. 443-451, 1975.

[82] R. C. Flagan, "On differential mobility analyzer resolution," Aerosol Science and Technology, vol. 30, no. 6, pp. 556-570, 1999.

[83] S. C. Wang and R. C. Flagan, "Scanning electrical mobility spectrometer," Aerosol Science and Technology, vol. 13, no. 2, pp. 230-240, 1990.

[84] D.-R. Chen, W. Li, and M.-D. Cheng, "Development of a multiple-stage differential mobility analyzer (MDMA)," Aerosol Science and Technology, vol. 41, no. 2, pp. 217-230, 2007.

[85] M. Giamarelou, M. Stolzenburg, and G. Biskos, "The multiple monodisperse outlet differential mobility analyzer: derivation of its transfer function and resolution," Aerosol Science and Technology, vol. 46, no. 9, pp. 951-965, 2012.

[86] M. Giamarelou, M. Stolzenburg, D.-R. Chen, and G. Biskos, "Comparison between the theoretical and experimental performance of a differential mobility analyzer with three monodisperse-particle outlets," Aerosol Science and Technology, vol. 47, no. 4, pp. 406-416, 2013.

[87] G. Oberdörster, V. Stone, and K. Donaldson, "Toxicology of nanoparticles: a historical perspective," Nanotoxicology, vol. 1, no. 1, pp. 2-25, 2007.

[88] K.-S. Woo, D.-R. Chen, D. Y. H. Pui, and W. E. Wilson, "Use of continuous measurements of integral aerosol parameters to estimate particle surface area," Aerosol Science and Technology, vol. 34, no. 1, pp. 57-65, 2001.

[89] M. I. Gini, C. G. Helmis, and K. Eleftheriadis, "Cascade epiphaniometer: an instrument for aerosol "Fuchs" surface area size distribution measurements," Journal of Aerosol Science, vol. 63, pp. 87-102, 2013.

[90] C. Asbach, H. Kaminski, D. von Barany et al., "Comparability of portable nanoparticle exposure monitors," The Annals of Occupational Hygiene, vol. 56, no. 5, pp. 606-621.

[91] D. J. Rader and P. H. McMurry, "Application of the tandem differential mobility analyzer to studies of droplet growth or evaporation," Journal of Aerosol Science, vol. 17, no. 5, pp. 771787, 1986.

[92] A. Schmidt-Ott, "In situ measurement of the fractal dimensionality of ultrafine aerosol particles," Applied Physics Letters, vol. 52, no. 12, pp. 954-956, 1988.

[93] G. Biskos, L. M. Russell, P. R. Buseck, and S. T. Martin, "Nanosize effect on the hygroscopic growth factor of aerosol particles," Geophysical Research Letters, vol. 33, no. 7, Article ID L07801, 2006.
[94] H. Fissan and D. Y. H. Pui, "Characterization of nanoparticles in the gas-borne state and on surface," Nanostructured Materials, vol. 9, no. 1-8, pp. 63-66, 1997.

[95] A. Maynard, D. Bowman, and G. Hodge, "The problem of regulating sophisticated materials," Nature Materials, vol. 10, no. 8, pp. 554-557, 2011.

[96] A. Voliotis, S. Benzantakos, M. Gaimarelou, M. Valenti, P. Kumar, and G. Biskos, "Nanoparticle emissions from traditional pottery manufacturing," Environmental Science: Process \& Impacts, 2014.

[97] B. J. Berne and R. Pecora, Dynamic Light Scattering, Dover, Mineola, NY, USA, 2000.

[98] R. Pecora, "Dynamic light scattering measurement of nanometer particles in liquids," Journal of Nanoparticle Research, vol. 2, no. 2, pp. 123-131, 2000.

[99] M. Filella, J. Zhang, M. E. Newman, and J. Buffle, "Analytical applications of photon correlation spectroscopy for size distribution measurements of natural colloidal suspensions: capabilities and limitations," Colloids and Surfaces A: Physicochemical and Engineering Aspects, vol. 120, no. 1-3, pp. 27-46, 1997.

[100] I. Montes-Burgos, D. Walczyk, P. Hole, J. Smith, I. Lynch, and K. Dawson, "Characterisation of nanoparticle size and state prior to nanotoxicological studies," Journal of Nanoparticle Research, vol. 12, no. 1, pp. 47-53, 2010.

[101] R. F. Domingos, M. A. Baalousha, Y. Ju-Nam et al., "Characterizing manufactured nanoparticles in the environment: multimethod determination of particle sizes," Environmental Science \& Technology, vol. 43, no. 19, pp. 7277-7284, 2009.

[102] K.-G. Wahlund and L. Nilsson, "Flow FFF-Basics and Key Applications," in Field-Flow Fractionation in Biopolymer Analysis, S. K. R. Williams and K. D. Caldwell, Eds., pp. 1-21, Springer, Vienna, 2012.

[103] M. Hassellöv, F. von der Kammer, and R. Beckett, "Characterisation of aquatic colloids and macromolecules by field-flow fractionation," in Environmental Colloids and Particles, K. J. Wilkinson and J. R. Lead, Eds., pp. 223-276, John Wiley \& Sons, New York, NY, USA, 2007.

[104] J. R. Runyon, M. Ulmius, and L. Nilsson, "A perspective on the characterization of colloids and macromolecules using asymmetrical flow field-flow fractionation," Colloids and Surfaces A: Physicochemical and Engineering Aspects, vol. 442, pp. 25-33, 2014.

[105] N. O'brien and E. Cummins, "Ranking initial environmental and human health risk resulting from environmentally relevant nanomaterials," Journal of Environmental Science and Health Part A, vol. 45, no. 8, pp. 992-1007, 2010.

[106] E. Bermudez, J. B. Mangum, B. Asgharian et al., "Long-term pulmonary responses of three laboratory rodent species to subchronic inhalation of pigmentary titanium dioxide particles," Toxicological Sciences, vol. 70, no. 1, pp. 86-97, 2002.

[107] E. Bermudez, J. B. Mangum, B. A. Wong et al., "Pulmonary responses of mice, rats, and hamsters to subchronic inhalation of ultrafine titanium dioxide particles," Toxicological Sciences, vol. 77, no. 2, pp. 347-357, 2004.

[108] D. Höhr, Y. Steinfartz, R. P. F. Schins et al., "The surface area rather than the surface coating determines the acute inflammatory response after instillation of fine and ultrafine $\mathrm{TiO}_{2}$ in the rat," International Journal of Hygiene and Environmental Health, vol. 205, no. 3, pp. 239-244, 2002.

[109] Z. Wang, E. Han, F. Liu, and W. Ke, "Thermal behavior of nano$\mathrm{TiO}_{2}$ in fire-resistant coating," Journal of Materials Science and Technology, vol. 23, no. 4, pp. 547-550, 2007. 
[110] C. E. H. Beaudrie, M. Kandlikar, and T. Satterfield, "From cradle-to-grave at the nanoscale: gaps in U.S. regulatory oversight along the nanomaterial life cycle," Environmental Science \& Technology, vol. 47, no. 11, pp. 5524-5534, 2013.

[111] S. M. Hussain, K. L. Hess, J. M. Gearhart, K. T. Geiss, and J. J. Schlager, "In vitro toxicity of nanoparticles in BRL 3A rat liver cells," Toxicology in Vitro, vol. 19, no. 7, pp. 975-983, 2005.

[112] P. Kocbek, K. Teskač, M. E. Kreft, and J. Kristl, “Toxicological aspects of long-term treatment of keratinocytes with $\mathrm{ZnO}$ and $\mathrm{TiO}_{2}$ nanoparticles," Small, vol. 6, no. 17, pp. 1908-1917, 2010.

[113] U. Henrich, R. Fuhst, S. Rittinghausen et al., "Chronic inhalation exposure of wistar rats and two different strains of mice to diesel engine exhaust, carbon black, and titanium dioxide," Inhalation Toxicology, vol. 7, no. 4, pp. 533-556, 1995.

[114] L. C. Renwick, D. Brown, A. Clouter, and K. Donaldson, "Increased inflammation and altered macrophage chemotactic responses caused by two ultrafine particle types," Occupational and Environmental Medicine, vol. 61, no. 5, pp. 442-447, 2004.

[115] D. B. Warheit, T. R. Webb, K. L. Reed, S. Frerichs, and C. M. Sayes, "Pulmonary toxicity study in rats with three forms of ultrafine- $\mathrm{TiO}_{2}$ particles: differential responses related to surface properties," Toxicology, vol. 230, no. 1, pp. 90-104, 2007.

[116] V. H. Grassian, P. T. O'Shaughnessy, A. Adamcakova-Dodd, J. M. Pettibone, and P. S. Thorne, "Inhalation exposure study of titanium dioxide nanoparticles with a primary particle size of 2 to $5 \mathrm{~nm}$," Environmental Health Perspectives, vol. 115, no. 3, pp. 397-402, 2007.

[117] J. Li, Q. Li, J. Xu et al., "Comparative study on the acute pulmonary toxicity induced by 3 and $20 \mathrm{~nm} \mathrm{TiO}$ primary particles in mice," Environmental Toxicology and Pharmacology, vol. 24, no. 3, pp. 239-244, 2007.

[118] R. Liu, L. Yin, Y. Pu et al., "Pulmonary toxicity induced by three forms of titanium dioxide nanoparticles via intra-tracheal instillation in rats," Progress in Natural Science, vol. 19, no. 5, pp. 573-579, 2009.

[119] S. P. Faux, C. L. Tran, B. G. Miller, A. D. Jones, C. Monteiller, and K. Donaldson, "In vitro determinants of particulate toxicity: the dose metric for poorly soluble dusts," HSE Res. Rep 154, 2003.

[120] U. The Royal Society \& The Royal Academy of Engineering: London, "Nanoscience and Nanotechnologies: Opportunities and Uncertainties," 2004, http://www.raeng.org.uk/news/publications/list/reports/nanoscience_nanotechnologies.pdf.

[121] T. Puzyn, B. Rasulev, A. Gajewicz et al., "Using nano-QSAR to predict the cytotoxicity of metal oxide nanoparticles," Nature Nanotechnology, vol. 6, no. 3, pp. 175-178, 2011.

[122] EC, "European Parliament and Council: Regulation (EC) No 1907/2006 of the European Parliament and of the Council of 18 December 2006 concerning the Registration, Evaluation, Authorisation and Restriction of Chemicals (REACH), establishing a European Chemicals Agency, amending Directive 1999/45/EC and repealing Council Regulation (EEC) No 793/93 and Commission; Regulation (EC) No $1488 / 94$ as well as Council Directive 76/769/EEC and Commission Directives 91/155/EEC, 93/67/EEC, 93/105/EC and 2000/21/EC. Official Journal of the European Union; 2006:1-849," 2006.

[123] EC, "European Union: Regulation (EC) No 1223/2009 of the European Parliament and of the Council of 30 November 2009 on Cosmetic Products. 2009, 59-209," 2009.

[124] G. Oberdorster, J. Ferin, and B. E. Lehnert, "Correlation between particle size, in vivo particle persistence, and lung injury," Environmental Health Perspectives, vol. 102, no. 5, pp. 173-179, 1994.
[125] G. Oberdörster, Z. Sharp, V. Atudorei et al., "Translocation of inhaled ultrafine particles to the brain," Inhalation Toxicology, vol. 16, no. 6-7, pp. 437-445, 2004.

[126] G. Oberdörster, Z. Sharp, V. Atudorei et al., "Extrapulmonary translocation of ultrafine carbon particles following wholebody inhalation exposure of rats," Journal of Toxicology and Environmental Health Part A, vol. 65, no. 20, pp. 1531-1543, 2002.

[127] M. Geiser, B. Rothen-Rutishauser, N. Kapp et al., "Ultrafine particles cross cellular membranes by nonphagocytic mechanisms in lungs and in cultured cells," Environmental Health Perspectives, vol. 113, no. 11, pp. 1555-1560, 2005.

[128] A. A. Keller, H. Wang, D. Zhou et al., "Stability and aggregation of metal oxide nanoparticles in natural aqueous matrices," Environmental Science \& Technology, vol. 44, no. 6, pp. 19621967, 2010.

[129] N. Gou, A. Onnis-Hayden, and A. Z. Gu, "Mechanistic toxicity assessment of nanomaterials by whole-cell-array stress genes expression analysis," Environmental Science \& Technology, vol. 44, no. 15, pp. 5964-5970, 2010.

[130] L. E. Murr and K. M. Garza, "Natural and anthropogenic environmental nanoparticulates: their microstructural characterization and respiratory health implications," Atmospheric Environment, vol. 43, no. 17, pp. 2683-2692, 2009.

[131] K. Aschberger, C. Micheletti, B. Sokull-Klüttgen, and F. M. Christensen, "Analysis of currently available data for characterising the risk of engineered nanomaterials to the environment and human health-lessons learned from four case studies," Environment International, vol. 37, no. 6, pp. 1143-1156, 2011.

[132] USEPA, "Proposed category for persistent, bioaccumulative and toxic chemicals," Fed Regist, vol. 63, no. 192, pp. 53417-53423, 1998.

[133] L. K. Teuschler, "Deciding which chemical mixtures risk assessment methods work best for what mixtures," Toxicology and Applied Pharmacology, vol. 223, no. 2, pp. 139-147, 2007.

[134] M. M. Mumtaz, W. A. Suk, and R. S. H. Yang, Principles and Practice of Mixtures Toxicology, WILEY-VCH Verlag GmbH \& Co. KGaA, Weinheim, Germany, 2010.

[135] J. H. Sung, J. H. Ji, J. D. Park et al., "Subchronic inhalation toxicity of silver nanoparticles," Toxicological Sciences, vol. 108, no. 2, pp. 452-461, 2009.

[136] Y. Fujitani, T. Kobayashi, K. Arashidani, N. Kunugita, and K. Suemura, "Measurement of the physical properties of aerosols in a fullerene factory for inhalation exposure assessment," Journal of Occupational and Environmental Hygiene, vol. 5, no. 6, pp. 380-389, 2008.

[137] J. Wang, G. Zhou, C. Chen et al., "Acute toxicity and biodistribution of different sized titanium dioxide particles in mice after oral administration," Toxicology Letters, vol. 168, no. 2, pp. 176185, 2007.

[138] E.-J. Park, E. Bae, J. Yi et al., "Repeated-dose toxicity and inflammatory responses in mice by oral administration of silver nanoparticles," Environmental Toxicology and Pharmacology, vol. 30, no. 2, pp. 162-168, 2010.

[139] M. van der Zande, R. J. Vandebriel, E. Van Doren et al., "Distribution, elimination, and toxicity of silver nanoparticles and silver ions in rats after 28-day oral exposure," ACS Nano, vol. 6, no. 8, pp. 7427-7442, 2012.

[140] Y. S. Kim, M. Y. Song, J. D. Park et al., "Subchronic oral toxicity of silver nanoparticles," Particle and Fibre Toxicology, vol. 7, article 20, pp. 2-11, 2010. 
[141] D. A. Winkler, E. Mombelli, A. Pietroiusti et al., "Applying quantitative structure-actitivyt relationship approaches to nanotoxicology: current status and future potential," Toxicology, vol. 313, pp. 15-23, 2013.

[142] V. C. Epa, F. R. Burden, C. Tassa, R. Weissleder, S. Shaw, and D. A. Winkler, "Modelling biological activities of nanoparticles," Nano Letters, vol. 12, pp. 5808-5812, 2012.

[143] T. C. Le, V. C. Epa, F. R. Burden, and D. A. Winkler, "Quantitative structure-property relationship modelling of diverse materials properties," Chemical Reviews, vol. 112, pp. 2889-2919, 2012.

[144] D. Fourches, D. Pu, C. Tassa et al., "Quantitative nanostructure-activity relationship modeling," ACS Nano, vol. 4, no. 10, pp. 5703-5712, 2010.

[145] I. Lynch and K. A. Dawson, "Protein-nanoparticle interactions," Nano Today, vol. 3, no. 1-2, pp. 40-47, 2008.

[146] M. R. Heal, P. Kumar, and R. M. Harrison, "Particles, air quality, policy and health," Chemical Society Reviews, vol. 41, pp. 66066630, 2012.

[147] P. Kumar, S. Jain, B. R. Gurjar et al., "New directions: can a "blue sky" return to Indian megacities?" Atmospheric Environment, vol. 71, pp. 198-201, 2013.

[148] P. Kumar, L. Morawska, W. Birmili et al., "Ultrafine particles in cities," Environment International, vol. 66, pp. 1-10, 2014.

[149] USEPA, U.S. Environmental Protection Agency, "Control of Nanoscale Materials under the Toxic Substances Control Act," U.S. Environmental Protection Agency, Office of Pollution Prevention and Toxics, 2014, http://www.epa.gov/ oppt/nano/\#nanomaterials.

[150] B. Nowack, N. Mueller, H. Krug, and P. Wick, "How to consider engineered nanomaterials in major accident regulations?" Environmental Sciences Europe, vol. 26, no. 1, p. 2, 2014. 

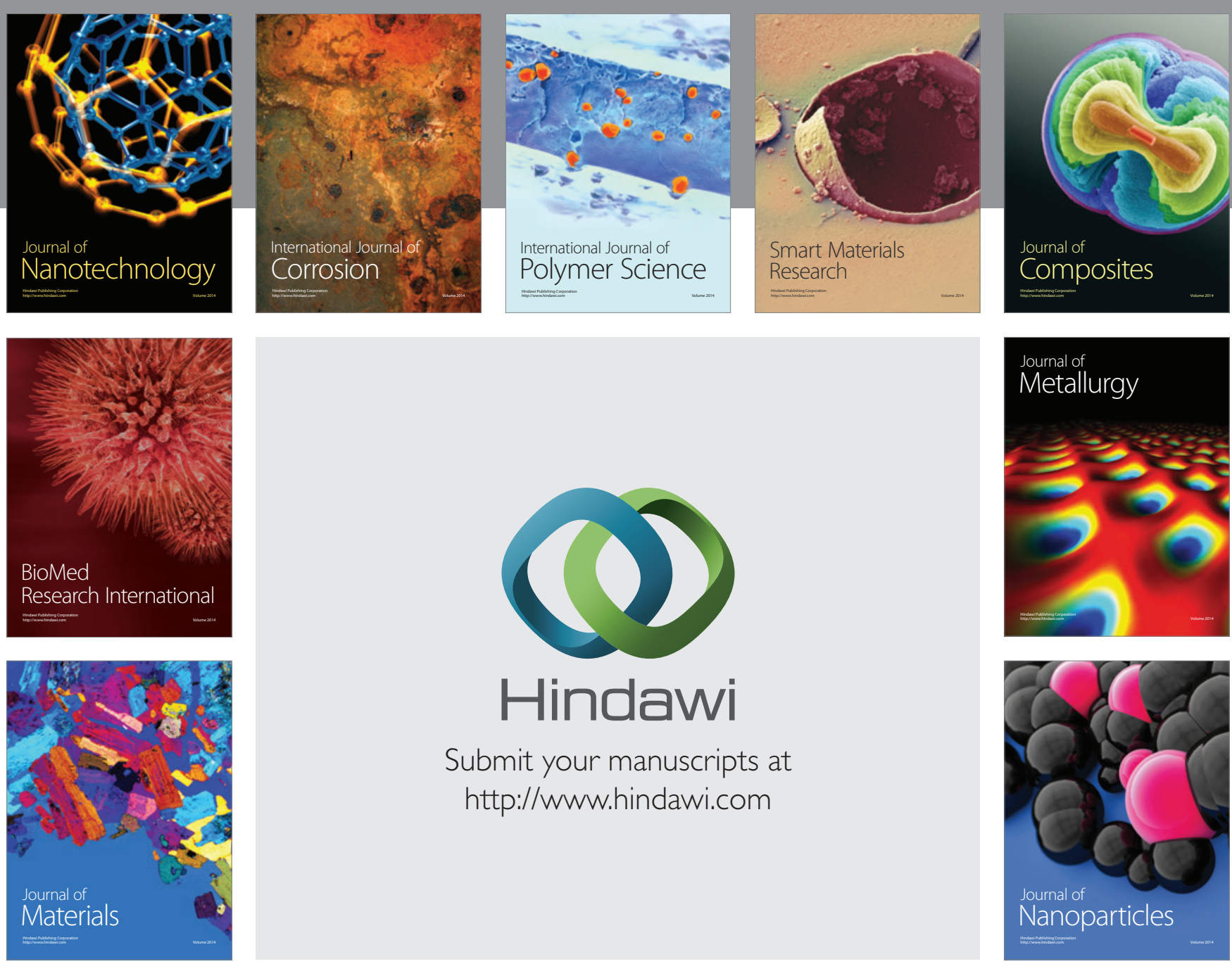

Submit your manuscripts at http://www.hindawi.com
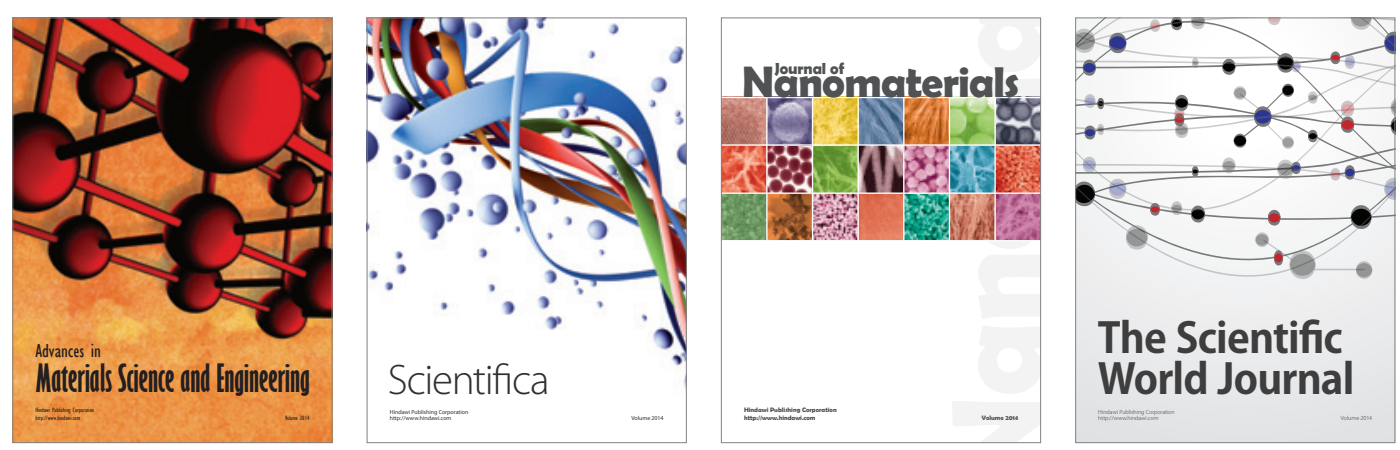

\section{The Scientific World Journal}
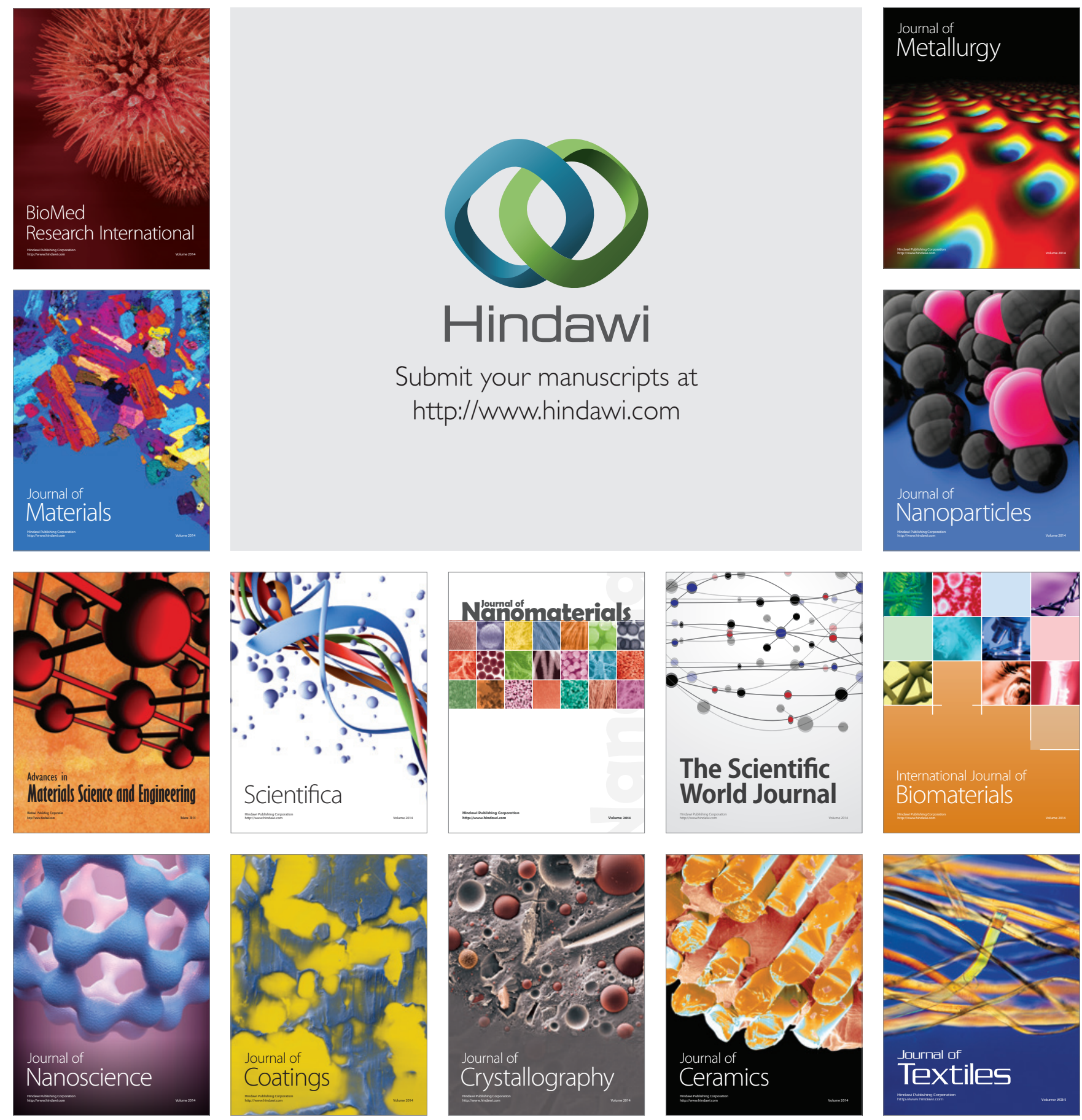